\title{
Biofloc Aquaculture as an Environmentally Friendly Climate Adaptation Option
}

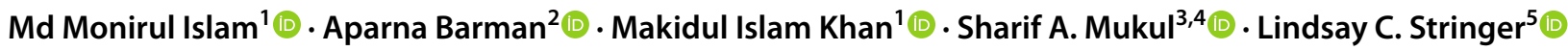

(C) The Author(s), under exclusive license to Springer Nature Singapore Pte Ltd. 2021

As discussions at COP26 draw to a close in Glasgow, it remains clear that there is a stark divide between the rate and magnitude at which the climate is changing and the world's political ability to respond to the challenge within the necessary time frame. Climate change continues to leave millions of people's livelihoods and environments vulnerable and precarious, especially in developing countries (IPCC 2014), while funding and donor support remain insufficient. Aside from making mitigation pledges, governments and development organizations are desperately seeking adaptation options that are effective, socio-economically feasible, have a limited environmental footprint, and which can be put in place quickly.

Aquaculture is one of the fastest growing sectors globally, supporting livelihoods of millions, and providing vital nutrition, despite growing concerns for its environmental impacts and its vulnerability to climate change (FAO 2020). The aquaculture sector is exposed and sensitive to climate hazards and impacts such as drought, flooding, heatwaves, sea level rise, salinity intrusion, and ocean acidification (Barange et al. 2018). People in developing countries in Asia and Africa with low levels of education, investment capacity and technological skills, and particularly women, are amongst the worst affected by climate change impacts.

Lindsay C. Stringer

lindsay.stringer@york.ac.uk

1 Department of Fisheries, University of Dhaka, Dhaka 1000, Bangladesh

2 Sustainability Services Ltd., Mirpur, Dhaka 1216, Bangladesh

3 Department of Earth and Environment, Florida International University, Miami, FL 33199, USA

4 School of Science, Technology and Engineering, University of the Sunshine Coast, Maroochydore DC, QLD 4556, Australia

5 Department of Environment \& Geography, University of York, Heslington, York YO10 5NG, UK
Biofloc aquaculture techniques can be a viable adaption option for the poorest and most marginalized, can support progress towards multiple Sustainable Development Goals (SDGs) and deserves increased attention and scrutiny.

Biofloc aquaculture was developed in the 1990s but is increasingly popular because of its huge benefits over traditional aquaculture. Juvenile fish (e.g., catfish, climbing perch, tilapia) are cultivated for 4-6 months in small tanks (e.g., 2000 L capacity) or large tanks (e.g., 25,000 L)/traditional ponds with little or no-water exchange (Kathia et al. 2017; dos Santos et al. 2021). Locally available formulated feeds provide nutrition daily - about 30\% less than conventional intensive aquaculture (Kathia et al. 2017). Probiotics are applied based on the tank requirements to convert unused feed, excreta and inorganic nitrogen waste into microbial biomass that is directly used as a suitable proteinaceous complementary feed for the fish (Khanjani and Sharifinia 2020). This process reduces waste, water exchange and feed requirements, production costs, and refines water quality, reducing greenhouse gas emissions compared to conventional aquaculture (Khanjani and Sharifinia 2020). Locally made cemented tanks or commercial biofloc tanks with $10,000 \mathrm{~L}$ capacity can be purchased from as little as USD 80 (Alibaba 2021). According to personal communications with farmers and government fisheries officers in rural Bangladesh, with other costs such as some minor equipment, feeds, fingerlings and little maintenance cost, $400-500 \mathrm{~kg}$ of fish can be harvested from this type of tank with a 30-40\% profit margin per year if people cultivate at home using household labor.

Biofloc aquaculture does however present some limitations. The amount of upfront investment may not be affordable to the extremely poor. To address this issue, development organizations could subsidize biofloc activities, or offer interest-free loans. Uninterrupted power supply is also important (Betanzo-Torres et al. 2020), so biofloc aquaculture will be suited only to the places where there is grid electricity supply that is at low risk of disruption during 


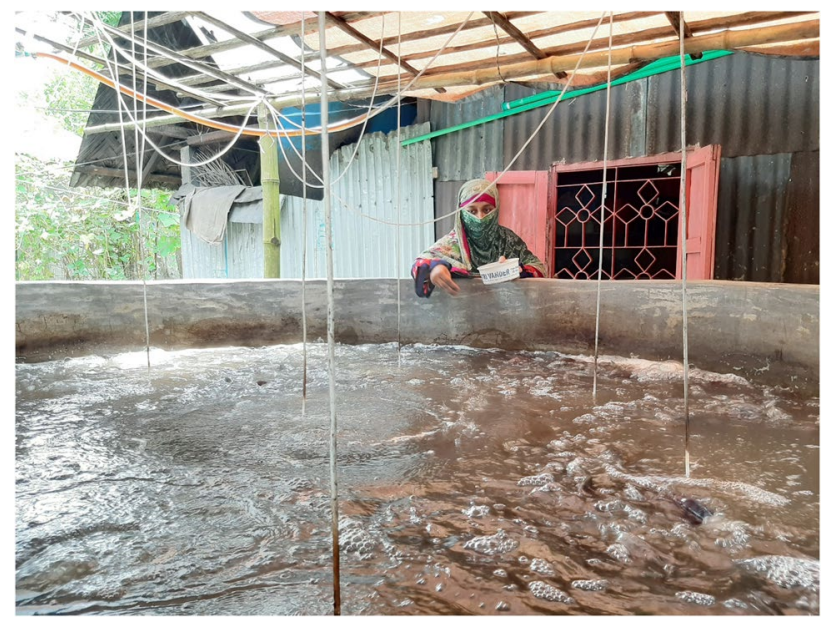

Fig. 1 Biofloc aquaculture in Noakhali, Bangladesh, operated by women. Photo credit: Md Alamgir Hossen

extreme climate events. A backup generator may be needed in case there is a temporary loss of power, increasing the cost. While solar power can be an alternative, this also will increase the investment cost, thus for the ultra/extreme poor, financial assistance and credit mechanisms will be needed.

Despite these challenges, in parts of Asia and Africa where there are water shortages or pond aquaculture is difficult, biofloc techniques can offer an important novel livelihood option (Pérez-Fuentes et al. 2013) that is less sensitive to climate hazards and impacts than conventional aquaculture. In addition to providing income and job opportunities for unemployed marginalized and female household members (Fig. 1), it can increase fish consumption among those that commonly lack sufficient nutrition and therefore improve food security, and does not require extensive land use changes. Biofloc thus offers potential to contribute to SDGs including SDG 1 (no poverty), SDG 2 (zero hunger), SDG 3 (good health and wellbeing), SDG 5 (gender equality), SDG 8 (decent work and economic growth), SDG 12 (responsible production and consumption), SDG13 (climate action), SDG 14 (life below water), and SDG 15 (life on land).

Development organizations, donors and NGOs, in collaboration with governments, should extend the biofloc technique to appropriate areas that are vulnerable to climate change, arranging training and providing basic equipment and/or finance for new biofloc farmers. Relevant inputs, credit, supply chain and marketing chains should also be developed, alongside further research investments to allow more comprehensive evaluation of the costs and benefits of biofloc.

\section{Declarations}

Conflict of interest On behalf of all authors, the corresponding author states that there is no conflict of interest.

\section{References}

Alibaba (2021) Waterproof PVC tarpaulin biofloc fish tank folding tilapia fish farming tank. https://www.alibaba.com/product-detail/ Waterproof-PVC-Tarpaulin-Biofloc-Fish-Tank_62557315833. html. Accessed 26 June 2021.

Barange M, Bahri T, Beveridge MC, Cochrane KL, Funge-Smith S, Poulain F (2018) Impacts of climate change on fisheries and aquaculture: synthesis of current knowledge, adaptation and mitigation options. FAO Fisheries and Aquaculture Technical Paper (FAO) eng no. 627 (ISBN 978-92-5-130607-9)

Betanzo-Torres EA, Piñar-Álvarez MDLÁ, Sandoval-Herazo LC, Molina-Navarro A, Rodríguez- Montoro I, González-Moreno RH (2020) Factors that limit the adoption of biofloc technology in aquaculture production in Mexico. Water 12:2775. https://doi. org/10.3390/w12102775

dos Santos DKM, Kojima JT, Santana TM, de Castro DP, Serra PT, Dantas NSM, da Fonseca FAL, Mariúba LAM, Gonçalves LU (2021) Farming tambaqui (Colossoma macropomum) in static clear water versus a biofloc system with or without Bacillus subtilis supplementation. Aquac Int 29:207-218. https://doi.org/10. 1007/s10499-020-00618-w

FAO (2020) The state of world fisheries and aquaculture 2020. FAO, Rome (ISBN: 978-92-5-132692-3)

IPCC (2014) Climate change 2014: synthesis report. Contribution of Working Groups I, II and III to the fifth assessment report of the Intergovernmental Panel on Climate Change. Geneva, Switzerland (ISBN 978-92-9169-143-2)

Kathia CM, del Carmen MDM, Aida HP, Jorge CM, Daniel BC (2017) Probiotics used in Biofloc system for fish and crustacean culture: a review. Int J Fish Aquat Stud 5:120-125

Khanjani MH, Sharifinia M (2020) Biofloc technology as a promising tool to improve aquaculture production. Rev Aquac 12:18361850. https://doi.org/10.1111/raq.12412

Pérez-Fuentes JA, Pérez-Rostro CI, Hernández-Vergara MP (2013) Pond-reared Malaysian prawn Macrobrachium rosenbergii with the biofloc system. Aquaculture 400:105-110. https://doi.org/10. 1016/j.aquaculture.2013.02.028 